\title{
Epidemiological Dynamics of a Bacterial Meningitis Outbreak in Two Districts in Northern Ghana
}

\author{
Franklin Asiedu-Bekoe ${ }^{1}$, Gideon Kwarteng Acheampong² \\ ${ }^{1}$ Disease Surveillance Department, Ghana Health Service, Accra, Ghana \\ ${ }^{2}$ Ensign College of Public Health, Kpong, Ghana \\ Email: kofi2711gmail.com, gideonacheampong@st.ensign.edu.gh
}

How to cite this paper: Asiedu-Bekoe, F. and Acheampong, G.K. (2016) Epidemiological Dynamics of a Bacterial Meningitis Outbreak in Two Districts in Northern Ghana. Open Access Library Journal, 3: e2993.

http://dx.doi.org/10.4236/oalib.1102993

Received: August 20, 2016

Accepted: October 9, 2016

Published: October 12, 2016

Copyright $\odot 2016$ by authors and Open Access Library Inc.

This work is licensed under the Creative Commons Attribution International

License (CC BY 4.0).

http://creativecommons.org/licenses/by/4.0/

(c) (i) Open Access

\begin{abstract}
Background: The Northern region of Ghana experienced an outbreak of bacterial meningitis between December, 2015 and May, 2016 with majority of cases recorded in Bole and Sawla-Tuna-Kalba districts. The epidemiological features of this outbreak were explored in these two districts. Methods: Data on the meningitis outbreak that occurred in the Northern region of Ghana between December, 2015 and May, 2016 was obtained from the Ghana Health Service's Department of Disease Surveillance. Specifically that on Sawla-Tuna-Kalba and Bole districts was extracted and analyzed. Results: Two different meningitis outbreaks occurred in two districts in Northern Region. Bole district had an outbreak due to $S$. pneumoniae while $N$. meningitids (N.m. W135) caused an outbreak in Sawla-Tuna-Kalba district. S. pneumoniae cases peaked earlier than $N$. meningitidis. The highest number of cases occurred in age groups 6 - 14 years followed by 15 - 44 years with deaths occurring in under 5 years and above 60 years. There was an association between outcome and age group, at a $\mathrm{p}$ value of 0.027 . Conclusion: Bacterial meningitis due to $S$. pneumoniae is increasingly becoming a major cause of meningitis outbreaks in Ghana. The differential periods of onset of pneumococcus and meningococcus outbreaks suggest that climatic factors responsible for these two diseases may be different and therefore it is prudent for studies to be carried to define more specific weather conditions favoring the spread of these two diseases in Ghana. With the extreme age groups recording fatalities, there is the need to give children and the elderly more attention to mitigate the effects of any future outbreak.
\end{abstract}

\section{Subject Areas}

Epidemiology 


\section{Keywords}

Streptococcus pneumoniae, Neisseria meningitidis, Pneumococcus, Meningococcus, Climatic Factors

\section{Introduction}

Bacterial meningitis is a major public health issue and remains one of the crucial causes of mortality and morbidity throughout sub-Saharan Africa. From post-mortem interviews, it has been estimated that about 2 percent of deaths in children under 5 years of age are due to meningitis, thus an overall 200,000 cases of bacterial meningitis cases have been extrapolated to occur in African children each year, 70,000 of these with fatal outcome [1]. The most important causative agents of bacterial meningitis are Neisseria meningitidis (the meningococcus), Streptococcus pneumoniae (the pneumococcus) and Haemophilus influenzae type b (Hib) [1] Haemophilus influenzae is well known for causing childhood meningitis, and $S$. pneumoniae mostly affects elderly, infants, and immunocompromised patients [2]. Meningococcal meningitis disease is very significant cause of death all over the world [1]. Invasive pneumococcal infection is as well a serious disease that usually occurs at the extremes of age (children and elderly population) and is associated with some predisposing illnesses. Alcoholism, HIV infection, splenectomy, connective tissue diseases, steroid use, diabetes mellitus and intravenous drug use, remain the most common risk factors for invasive pneumococcal infection [3]. Both invasive pneumococcal disease (IPD) and meningococcal disease (MD) show seasonal patterns.

A region of sub-Saharan Africa extending from Ethiopia to Senegal, designated "the African meningitis belt", has been particularly vulnerable to meningococcal disease epidemics [4]. In addition to sporadic disease which occurs mainly during the annual dry season, meningitis epidemics have occurred in the African meningitis belt every $8-12$ years over the past 100 years [4]. Ghana along with other countries in West and East Africa lies within the African meningitis belt (as shown in Figure 1). Specifically and with reference to Figure 1 and Figure 2, the Northern parts of Ghana are the areas that lie in this belt and subsequently experience seasonal outbreaks of meningitis [5]. In the African meningitis belt, epidemics of serogroup A meningococci occur in cycles (every 8 -12 years), and each epidemic wave follows a multiyear crescendo-decrescendo pattern [5]. Disease incidence is seasonally dependent, peaking during the dry season (December-May) and declining rapidly with the onset of the rainy season [4].

Studies have found $S$. pneumoniae to be the most important causative agent of bacterial meningitis in certain areas. The incidence in these areas is $10-20$ cases $/ 100,000$ people/year, which is 10 times higher than that in Western Europe and the United States [6]. Cases of $S$. pneumoniae meningitis occur throughout the year, and most studies report the youngest ( 2 years) and the oldest (160 years) people to be at the greatest 


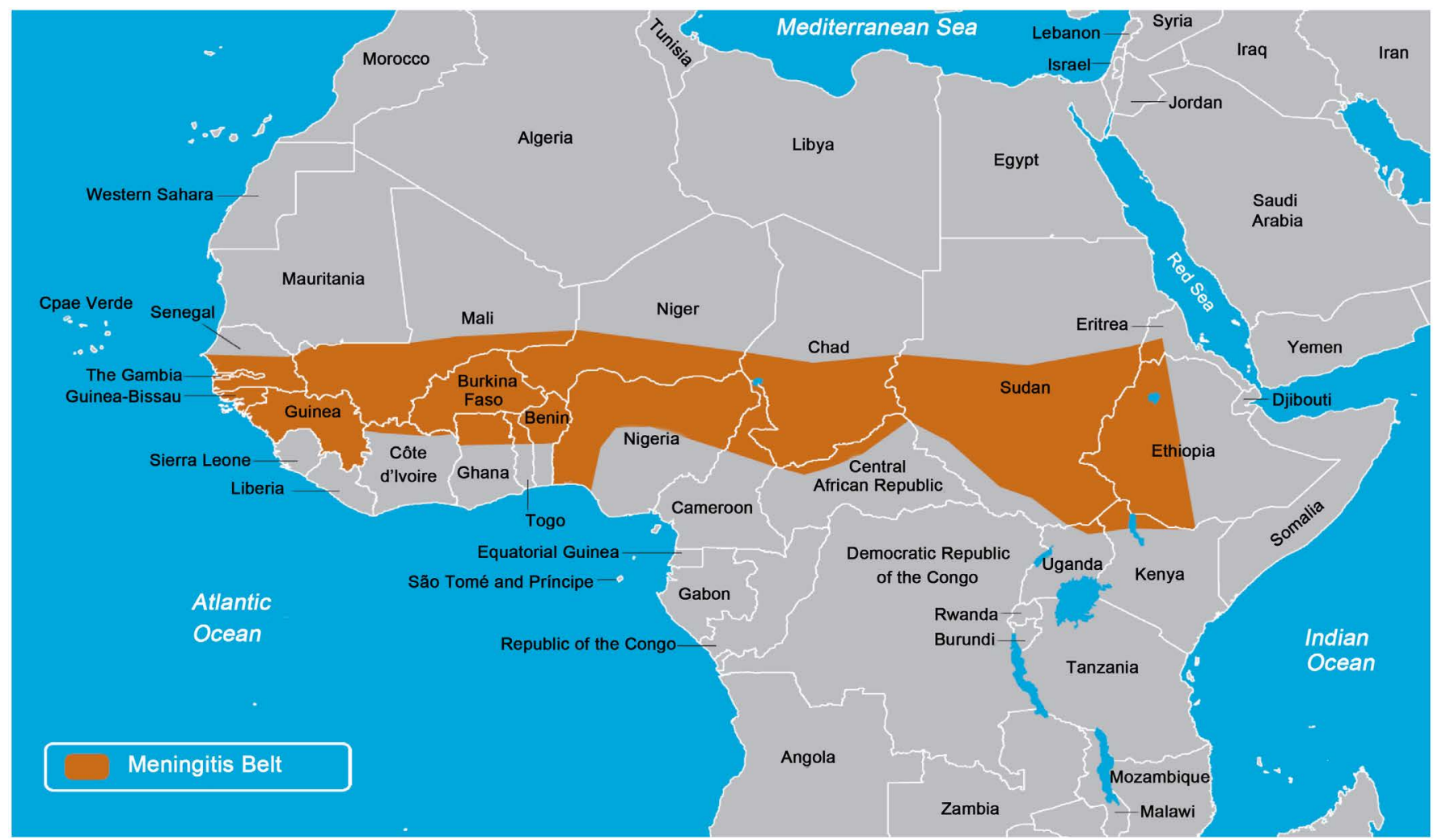

Figure 1. Map of Africa highlighting the African meningitis belt.

risk [7]. For unknown reasons, the case-fatality rate for pneumococcal meningitis (50\%) is 5 - 10 times higher than that for meningococcal meningitis. A study on an outbreak of serotype 1 Streptococcus pneumoniae meningitis in Northern Ghana with features that were characteristic of Neisseria meningitidis meningitis epidemics by Leimkugel et al., in 2005 revealed that cases of both meningococcal and pneumococcal meningitis were concentrated in the dry season, suggesting that similar factors might have triggered both types of outbreaks. The pneumococcal meningitis cases peaked 1 2 months earlier than the meningococcal meningitis cases. This finding may either reflect a very high invasive capacity of the causative clonal complex of serotype 1 pneumococci or indicate that the factors that trigger pneumococcal and meningococcal meningitis are not entirely the same. The present study was conducted following the bacterial meningitis outbreak that occurred in the Northern regions of Ghana and the Brong Ahafo region between December 2015 and May 2016. The Bole and Sawla-Tuna-Kalba districts were the selected districts used as case studies since they recorded relatively higher number of cases in comparison with cases in other districts. This study sets out to describe the epidemiological features of the two different outbreaks of bacterial meningitis in both Bole and Sawla-Tuba-Kalba districts. Specifically, the study examines the variation in the period of onset of S. pneumoniae and $N$. meningitides outbreaks in the two districts and as well describes the age and sex distribution of bacterial meningitis ( $S$. pneumoniae and N. meningitidis) in the two districts. 


\section{Study Site}

The Northern Region, which occupies an area of about 70,383 square kilometers, is the largest region in Ghana in terms of land area. It shares boundaries with the Upper East and the Upper West Regions to the north, the Brong Ahafo and the Volta Regions to the south, and two neighboring countries, the Republic of Togo to the east, and La Cote d' Ivoire to the west. The harmattan winds, which occur during the months of December to early February, have considerable effect on the temperatures in the region, which may vary between $14^{\circ} \mathrm{C}$ at night and $40^{\circ} \mathrm{C}$ during the day. Humidity, however, which is very low, mitigates the effect of the daytime heat. The rather harsh climatic condition makes the cerebrospinal meningitis thrive, almost to endemic proportions, and adversely affects economic activity in the region [8] [9].

The Sawla-Tuna-Kalba district occurs on latitude $9.2732^{\circ} \mathrm{N}$ and Longitude $2.4135^{\circ} \mathrm{W}$ and is located in the North Western part of the Northern Region of Ghana as shown in Figure 2 and carved out of the Bole District. It shares boundaries with Wa West District to the North, Bole District to the South, West Gonja District to the East and La Cote D'Ivoire to the West at the Black Volta. The population size is 99,863 ; forming $4 \%$ of the Northern Regional population with $86 \%$ of its population is rural. The district is predominantly rural with a rural population of 85,918 (93.8\%) and an urban population of $13,945(6.2 \%)$ [8].

The Bole district occurs on the latitude $9.034^{\circ} \mathrm{N}$ and Longitude $2.485^{\circ} \mathrm{W}$ and is located in the North Western part of the Northern Region of Ghana as shown in Figure 2. It is bordered to the north by the Sawla-Tuna-Kalba district, to the west by the republic of Cote d'ivoire with the Black Volta as the boundary. It also shares boundaries

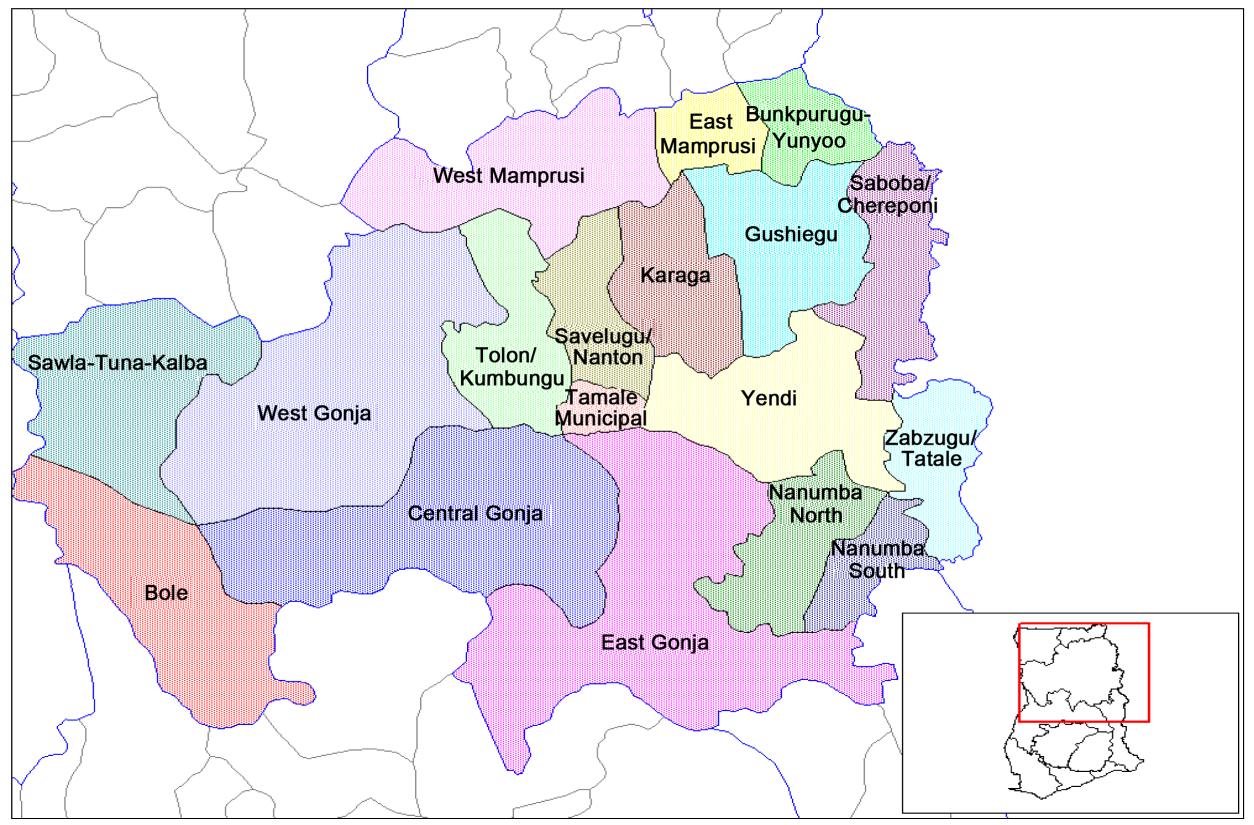

Figure 2. Maps of Ghana (bottom right) and the Northern Region (left) highlight in geo-political zones including Sawla-Tuna-Kalba and the Bole Districts. 
with the West Gonja district at the East and to the south by the Wenchi municipal in Brong Ahafo region. It has a population size of 121,009 ; forming $4.9 \%$ of the Northern Regional population with $67.6 \%$ of its population is rural [8].

\section{Methods}

Data on the meningitis outbreak that occurred in the Northern region of Ghana between December 2015 and May 2016 was obtained from the Ghana health service's Department of Disease Surveillance. Information specifically on the Sawla-Tuna-Kalba and Bole districts was extracted from the data and subsequently used for all quantitative data analysis. The number of cases from the two districts was obtained and variables such as age, sex, district of residence, district of reportage, health facility reported, date seen at health facility, date of onset, laboratory results and outcome, were all extracted from the data and was used for analysis.

\section{Data Analysis}

STATA statistical software package (Stata Corp.2007. Stata Statistical Software. Release 12.StataCorp LP, College Station, TX, USA) was used for all univariate and bivariate analysis. Analysis was done based on set aims and objectives. All data was double entered into the Microsoft excel software spread sheet and later converted to fit the used softwares. A Fisher's exact test was used to test for association between various variables of the cases. The variables that were subjected to the Fisher's exact test for association were as follows:

- Sex of cases versus laboratory results of cases;

- Outcome of cases (dead or alive) versus age group of cases;

- Age group versus laboratory results of cases.

\section{Results}

A total of 83 suspected cases of bacterial meningitis were recorded in both Bole and Sawla-Tuna-Kalba districts between December 2015 and May 2016. Out of these suspected cases, 56 were laboratory confirmed to be cases of bacterial meningitis with 22 cases in Bole and 34 recorded in Sawla-Tuna-Kalba.

From Figures 3-6 it can be observed that between December, 2015 and May, 2016 there were two different outbreaks of bacterial meningitis occurring at two different times in two districts. Table 1 shows a breakdown of the distribution of the cases across the two districts. The bacterial meningitis outbreak in Bole was due to high numbers of $S$. pneumoniae cases (as observed in Table 1), S. pneumoniae cases exceeded the alert and epidemic thresholds between weeks 2 and 3, this can observed in Figure 3 and Figure 4. On the other hand the bacterial meningitis outbreak in the Sawla-Tuna-Kalba district was due to $N$. meningitidis cases (N·m W135 strain) as observed in Table $1, N$. meningitidis cases exceeded the alert and epidemic thresholds between weeks 10 and 12, this can observed in Figure 5 and Figure 6.

Figure 7 shows a graph displaying the various age groups of the cases plotted against 
the disease outcome(whether the case died or lived)for the two districts. It is observed that death cases appeared only in the extreme age groups, that is $<5$ and $\geq 60$ years. The highest number of cases occurred in age groups 6 - 14 years followed by $15-44$ years. A subsequent look at Table 2 shows no significant association between sex and laboratory result as a p-value of 0.514 was recorded. On the other hand, a test for association bet-

\section{GRAPH SHOWING NUMBER OF BACTERIAL MENINGITIS CASES BY EPID WEEK IN BOLE DISTRICT}

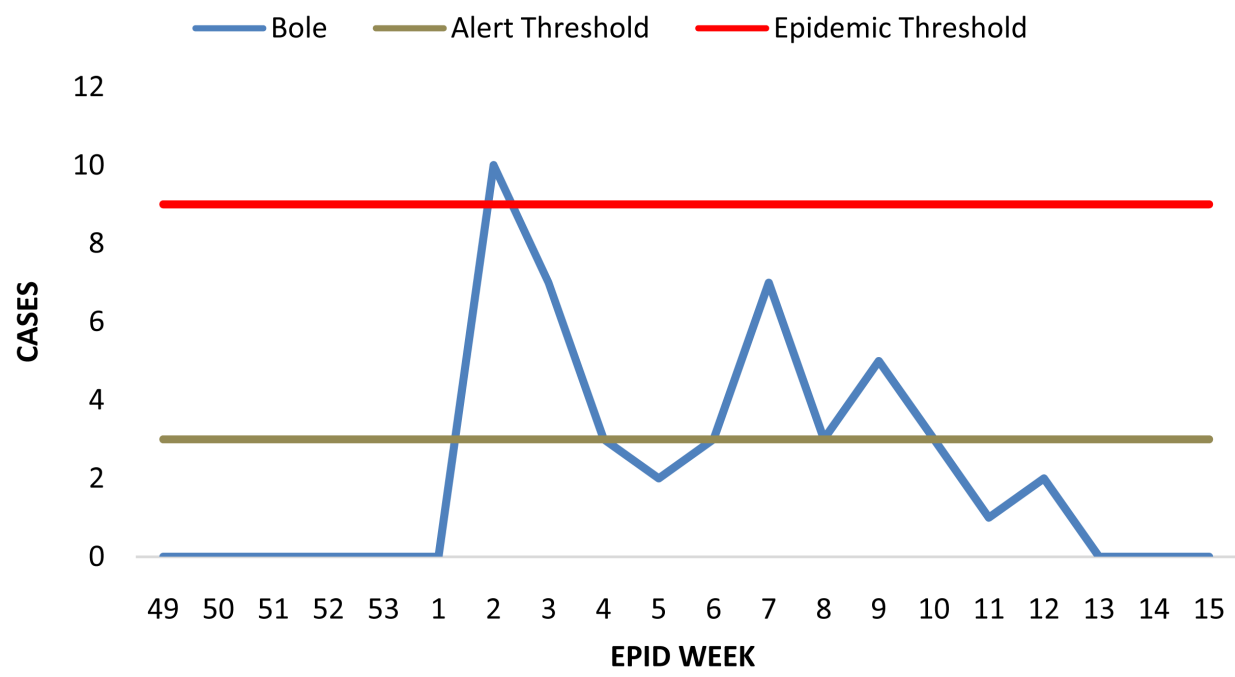

Figure 3. Distribution of reported bacterial meningitis cases recorded against the EPID Week in the Bole district.

Table 1. Distribution of bacterial meningitis cases in bole and Sawla-Tuna-Kalba.

\begin{tabular}{|c|c|c|c|c|c|c|c|c|c|c|}
\hline \multicolumn{11}{|c|}{ Summary of distribution of $S$. pneumoniae and $N$. meningitis cases in the Bole and Sawla-Tuna-Kalba } \\
\hline Bole 12 & 12 & \multicolumn{3}{|c|}{10} & \multicolumn{6}{|c|}{22} \\
\hline Sawla-Tuna-Kalba & 8 & \multicolumn{3}{|c|}{26} & \multicolumn{6}{|c|}{34} \\
\hline \multicolumn{11}{|c|}{$\begin{array}{l}\text { Host distribution of } S \text {. pneumoniae and } N \text {. meningitis cases in the Bole } \\
\text { and Sawla-Tuna-Kalba districts by age, sex, outcome }\end{array}$} \\
\hline \multirow{3}{*}{ District } & Causative & \multicolumn{5}{|c|}{ Age distribution (years) } & \multicolumn{2}{|c|}{ Sex } & \multicolumn{2}{|c|}{ Outcome } \\
\hline & Organism & $<5$ & $6-14$ & $15-44$ & $45-60$ & $\geq 60$ & $\mathbf{M}$ & $\mathbf{F}$ & Alive & Dead \\
\hline & N. meningitis (N.m-W135) & 2 & 6 & 1 & 1 & 0 & 6 & 4 & 8 & 2 \\
\hline Bole & S. pneumoniae (S.p.) & 0 & 2 & 9 & 1 & 0 & 9 & 3 & 6 & 6 \\
\hline \multirow[t]{2}{*}{ Sawla-Tuna-Kalba } & S. pneumoniae (S.p) & 1 & 3 & 3 & 0 & 1 & 3 & 5 & 6 & 2 \\
\hline & Total (N.m and S.p cases) & 7 & 15 & 9 & 1 & 2 & 12 & 22 & 32 & 2 \\
\hline
\end{tabular}

Univariate analysis was carried out using STATA statistical software package (StataCorp.2007. Stata statistical Software. Release 12 .StataCorp LP, College Station, TX, USA). 


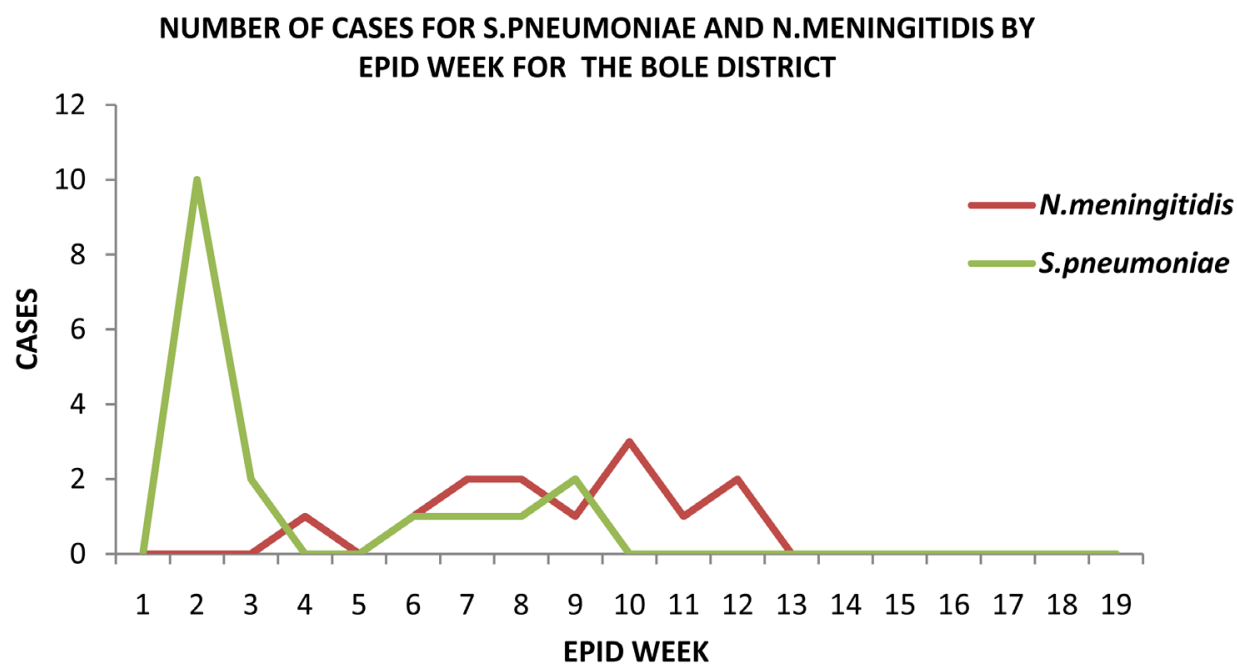

Figure 4. Graph displaying the number of different bacterial meningitis cases ( $S$. pneumoniae and $N$. meningitidis) recorded against the EPID Week in the Bole district.

\section{GRAPH SHOWING NUMBER OF BACTERIAL MENINGITIS CASES BY EPID WEEK IN THE SAWLA-TUNA-KALBA DISTRICT}

- Sawla-Tuna-Kalba _ Alert Threshold _ Epidemic Threshold

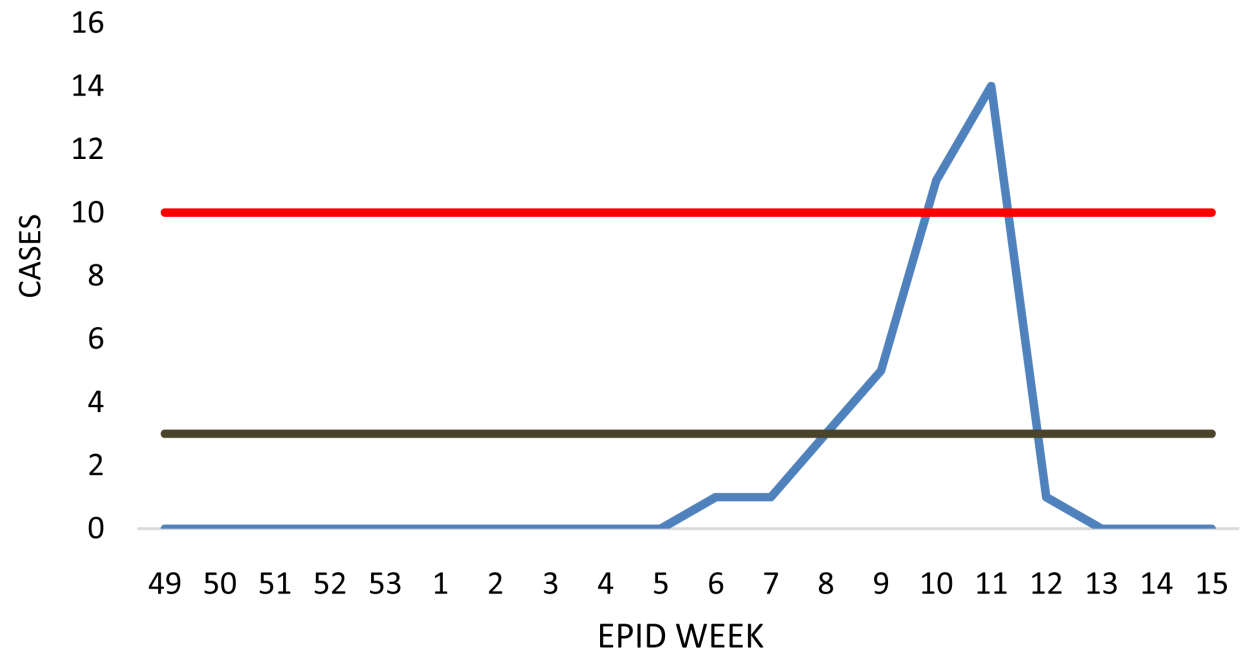

Figure 5. Distribution of reported bacterial meningitis cases against the EPID week in the SawlaTuna-Kalba district.

Table 2. Summary bivariate analysis between various variables.

\begin{tabular}{cc}
\hline Test for association between variables age group, outcome, laboratory result \\
\hline Variable & Fisher's exact test for association (p-value) \\
\hline Sex versus laboratory result & 0.514 \\
Outcome versus age group & 0.027 \\
Age group versus laboratory result & 0.591 \\
\hline
\end{tabular}




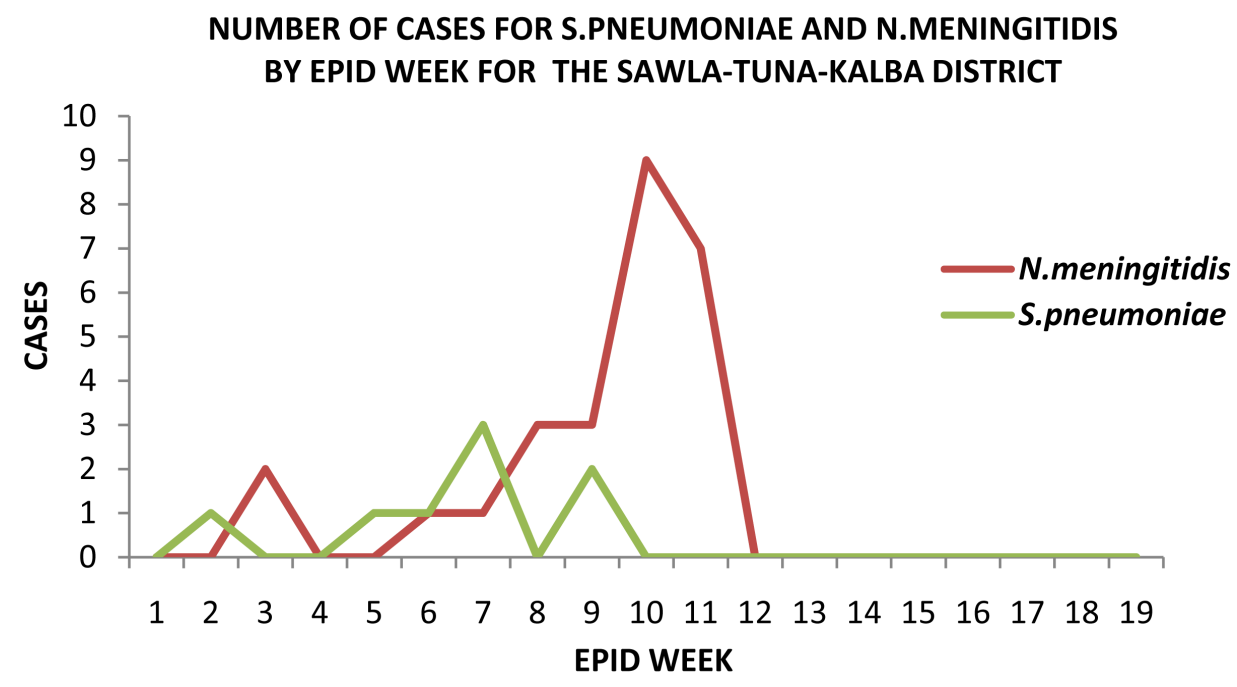

Figure 6. Graph displaying the number of different bacterial meningitis cases $(S$. pneumoniae and N. meningitidis) recorded against the EPID Week in the Sawla-Tuna-Kalba district.

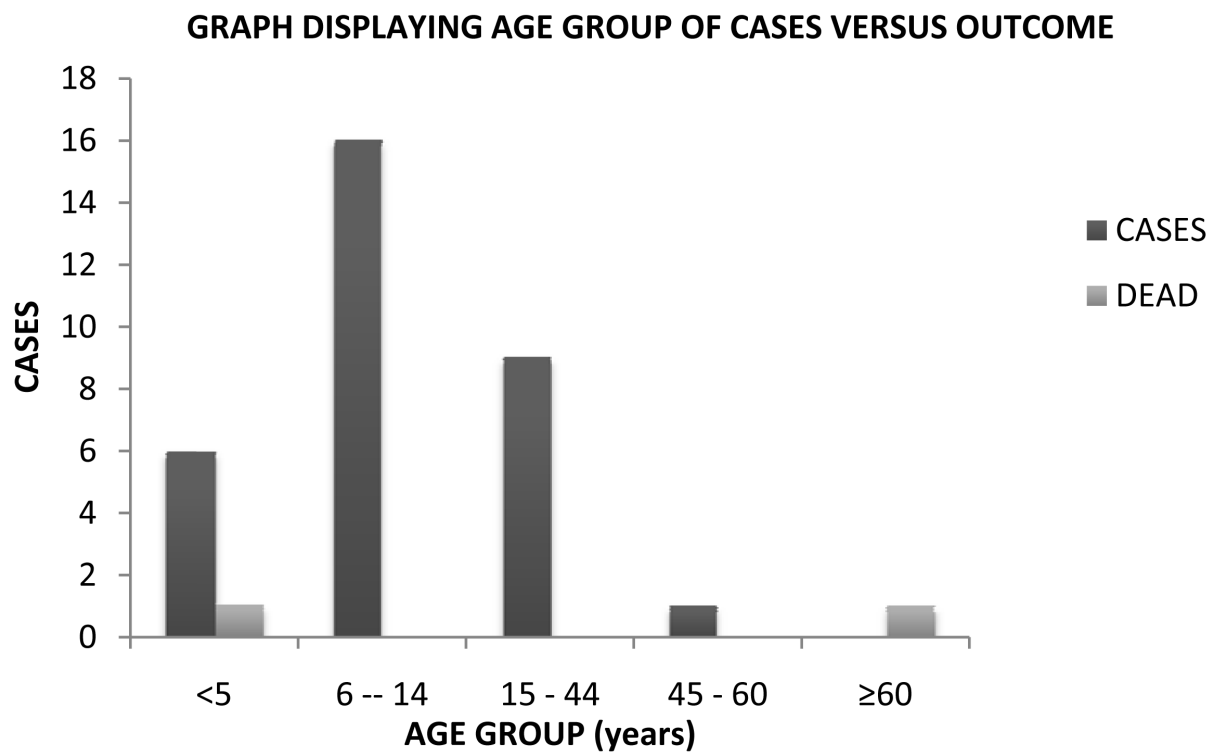

Figure 7. Graph displaying age group of cases versus outcome (dead or alive) for both districts.

ween outcome and age group indicated a $p$-value of 0.027 , confirming the issue of a significant association between outcome (dead or alive) and age group of cases in both districts. Again, Figure 4 and Figure 6 demonstrate that in both districts $S$. pneumoniae peaked earlier than N. meningitidis. For the Bole district, it can be observed from Figure 4 that cases of $S$. pneumoniae peaked in week 2 while that of $N$. meningitidis peaked in week 10. A look at Figure 6 also shows that cases of $S$. pneumoniae peaked in week 7 while cases of $N$. meningitids peaked in week 10 for the Sawla-Tuna-Kalba district.

\section{Discussion}

Neisseria meningitidis has been the major cause of most meningitis outbreaks in Ghana 
and subsequently the dominant causative organism of various forms of bacterial meningitis in Ghana, it has been described in various studies as being uniquely able to cause meningitis outbreaks [4]-[6] [12] [18]. Streptococcus pneumoniae bacterium however has previously been the cause of certain meningitis outbreaks in Ghana, the Kassena-Nankana District of northern Ghana which lies in the African meningitis belt, where epidemics of bacterial meningitis reoccur every 8 - 12 years experienced meningitis outbreaks due to $N$. meningitidis as well as $S$. pneumoniae between 1998 and 2003 [4]. A study by Leimkugel et al., in the Kassena-Nankana District on an outbreak of serotype 1 Streptococcus pneumoniae meningitis in Northern Ghana with features that were characteristic of Neisseria meningitidis meningitis epidemics revealed that the $S$. pneumoniae ST217 clonal complex represented a hyper virulent lineage with a high propensity to cause meningitis [4], the results predicted that this lineage had the potential to cause subsequent epidemics, that outbreak as well exhibited epidemiological and bacteriological features that were characteristic of African meningococcal meningitis epidemic including strong seasonality and a broad host age range a development similar to this current study. Identical to our study, an increase in pneumococcal meningitis cases was accompanied by a successive outbreak of meningococcal meningitis. With respect to the seasonal and periodic nature of occurrence of meningitis outbreaks and on the phase of the findings by Leimkugel et al., in 2005, an occurrence of a subsequent bacterial meningitis outbreak due to $S$. pneumoniae was predictable.

This study established that between the periods of December 2015 and May 2016, there were two different outbreaks occurring at two different times in two different districts. The Bole district experienced an outbreak of pneumococcal meningitis ( $S$. pneumoniae) between weeks 2 and 3 whiles Sawla-Tuna-Kalba experienced an outbreak of meningococcal meningitis ( $N$. meningitidis) between weeks 10 and 12 . Even though $S$. pneumoniae cases appeared earlier than $N$. meningitidis in the Sawla-TunaKalba districts, those cases recorded did not exceed the epidemic threshold for a declaration of a meningitis outbreak. There have been various studies regarding the weather conditions favorable for meningitis outbreaks [10]-[13], a study by Abdulai Adams Forgor on meningococcal and pneumococcal meningitis in the Northern region of Ghana mentioned that, the climatic factors that influence the incidence of pneumococcal meningitis and meningococcal meningitis were found to be similar but not always the same. The duration of a preceding absence of rainfall appears to be the best predictor of both pneumococcal and meningococcal meningitis outbreaks. Outbreaks of meningococcal meningitis are best predicted by concurrent decrease in rainfall with increase in weekly mean maximum temperature [14]. Those of pneumococcal meningitis are immediately triggered by just a concurrent decrease in rainfall [14]. This phenomenon of the occurrence of different outbreaks at two different times in the two districts as revealed in this study can to some extent be attributed to a variation in the climatic conditions between the two different periods of occurrence of both outbreaks.

This meningitis outbreak however was exclusively characterized by extremely dry conditions and as previously mentioned was followed by a variation in onset of pneu- 
mococcus and meningococcus. Other studies have also suggested that differences in climatic conditions between the early dry season (which includes the harmattan period, with its cold nights and extremely dusty air) and the late dry season (which brings intense heat) may be relevant [4] [11] [15] [16]. However, studies pertaining to the exact weather conditions with regards to temperature or humidity within the dry season that trigger meningococcus and pneumococcus have not been extensively explored in Ghana. Furthermore, outbreaks of pneumococcal meningitis that have previously occurred in Ghana and Burkina Faso both showed similar seasonal pattern to that of classical meningococcal epidemics in Africa [6] with increase in number of cases beginning little earlier for pneumococcal meningitis, which is similar to the results of this study. This again buttresses the fact that the climatic factors responsible for setting off outbreaks of these 2 infections are similar but not identical [17]. In this study, the pneumococcal meningitis cases peaked at least 3 weeks earlier than the meningococcal meningitis cases in both districts. Leimkugel et al., in 2005 also found out that, the pneumococcal meningitis cases peaked $1-2$ months earlier than the meningococcal meningitis cases [4], this finding may again either reflect the fact that the factors that trigger pneumococcal and meningococcal meningitis again are not entirely the same or there is a very high invasive capacity of the causative organism $S$. pneumoniae compared to Neisseria meningitidis as mentioned by Leimkugel et al., in 2005.

In a further development, the results obtained showed that there was no significant association between sex and contraction of both meningitis diseases as observed in Table 2, an assertion further supported by a number of studies including a prospective study on Neisseria meningitidis in the Northern region in 2002 [4] [5] [19] and in effect demonstrates that the entire population is at risk of meningitis irrespective of sex. However a much circumspective look at the results shows that the number of cases recorded for females was slightly higher than that of males (27 males to 29 females), even though this is not statistically significant, the aforementioned study [5], showed that females were more likely to acquire Neisseria lactamica than males, with $N$. lactamica more prevalent in females than males. It is worth noting that public health systems pay particular attention to women and children in light of this development.

Studies have demonstrated the occurrence of this disease (bacterial meningitis) in extreme age groups (that is $<5$ and $\geq 60$ years) [4]-[6] [10]. The results of this study showed that there was a strong association between the outcome (dead or alive) and the age group ( $\mathrm{p}$-value $=0.027$ ), which implied that the outcome of an individual, (that is to say whether an individual survives or dies) has ties with the age group of that particular individual. Again it is imperative to prioritize these extreme age group in terms of disease control and prevention since they represent the age groups at risk of acquiring this disease, individuals within these age brackets appear to have weaker immune systems [10] [20]. This view is further established by Figure 7 in the results section where the only deaths recorded for meningitis disease was for the extreme age groups.

\section{Conclusion}

Pneumococcal meningitis is increasingly becoming a major cause of bacterial meningi- 
tis outbreak in Ghana and public health systems should be alerted to this development in any case of an occurrence of a subsequent meningitis outbreak. In light of the already established seasonality of meningitis as well as the differential periods of onset of pneumococcus and meningococcus, climatic factors responsible for these two diseases are different and thus there is an urgent need for studies to be carried to ascertain more specific weather conditions in terms of temperature, humidity and precipitation favoring the spread of both pneumococcus and meningococcus in Ghana. With the extreme age groups (that is $<5$ years and $\geq 60$ years) recording fatalities and females identified as the sex recording majority of meningitis cases, there is the need to give women, children and the elderly enough attention to mitigate the effects of any future outbreak as part of recommendations to improve meningitis disease prevention and control.

\section{Acknowledgements}

We thank the leadership of the Ghana Health Service's Department of Disease Surveillance and the administrative staff of the Ensign College of Public Health, Kpong E/R, Ghana. We as well acknowledge the willing inputs of the following subjects in the study; Mr. Kwame Owusu Acheampong, Mr. Kwame Kodom Achempem and Mr. Isaac Baffoe Nyarko all of the Department of Disease Surveillance. Finally we duly acknowledge the contribution of Collins Kankam MD, former affiliate of Inova Fairfax Hospital. VA, USA.

\section{Conflict of Interest}

We (Dr. Franklin Asiedu-Bekoe and Gideon Kwarteng Acheampong), in our capacity as authors of this manuscript epidemiological dynamics of a bacterial meningitis outbreak in two districts in Northern Ghana have duly read and understood the policy on declaration of interests of the Open Access Library (OALib) Journal and hereby declare that there is no conflict of interest regarding our research. Thank you.

\section{References}

[1] Peltola (1983) Meningococcal Disease: Still with Us. 71-90.

[2] Leimkugel, J. (2006) Clonal Waves of Meningococcal and Pneumococcal Meningitis in a Region of the Meningitis Belt of Sub-Saharan Africa. PLoS Medicine, 4, e101. http://dx.doi.org/10.1371/journal.pmed.0040101

[3] Taylor, S.C. (1999) Unusual Manifestation of Pneumococcal Infection. American Journal of Medicine, 107, 12-27.

[4] Leimkugel, J., Adams Forgor, A., Gagneux, S., Pflüger, V., Flierl, C., Awine, E., Naegeli, M., Dangy, J.-P., Smith, T., Hodgson, A. and Pluschke, G. (2005) An Outbreak of Serotype 1 Streptococcus pneumoniae Meningitis in Northern Ghana with Features That Are Characteristic of Neisseria Meningitidis Meningitis Epidemics. The Journal of Infectious Diseases, 192, 192-199. http://dx.doi.org/10.1086/431151

[5] Gagneux, S.P., Hodgson, A., Smith, T.A., Wirth, T., Ehrhard, I., Morelli, G., Genton, B., Binka, F.N., Achtman, M. and Pluschke, G. (2002) Prospective Study of a Serogroup X Neisseria Meningitidis Outbreak in Northern Ghana. The Journal of Infectious Diseases, 
185, 618-626. http://dx.doi.org/10.1086/339010

[6] Mar ID, C.M. and Denis, F. (1979) Epidemiologic Features of Pneumococcal Meningitis in Africa: Clinical and Serotypical Aspects.

[7] Achtman, M. (1999) Epidemic Spread and Antigenic Variability of Neisseria Meningitis. Trends in Microbiology, 3, 41-53.

[8] Ghana Statistical Service (GSS) (2014) District Analytical Report: Bole District. p. 77.

[9] Ghana Statistical Service (2010) District Analytical Report: East Mamprusi District.

[10] Burckhardt, I., Burckhardt, F., Van Der Linden, M., Heeg, C. and Reinert, R.R. (2010) Risk Factor Analysis for Pneumococcal Meningitis in Adults with Invasive Pneumococcal Infection. Epidemiology and Infection, 138, 1353-1358. http://dx.doi.org/10.1017/S0950268809991683

[11] Ayden, M.H., Orgor, A.A.F., Opson, T.H., Kweongo, P.A., Odgson, A.H., Onaghan, A.M., Iedinmyer, C.W., Oksas, T.Y., Homson, M.C.T., Rzaska, S.T. and Andya, R.P. (2012) The Role of Weather in Meningitis Outbreaks in Navrongo, Ghana: A Generalized Additive Modeling Approach. Journal of Agricultural, Biological, and Environmental Statistics, 17, 442-460.

[12] Codjoe, S.N.A. and Nabie, V.A. (2014) Climate Change and Cerebrospinal Meningitis in the Ghanaian Meningitis Belt. International Journal of Environmental Research and Public Health, 11, 6923-6939. http://dx.doi.org/10.3390/ijerph110706923

[13] Azevedo, L.C.P., Toscano, C.M. and Bierrenbach, A.L. (2013) Bacterial Meningitis in Brazil: Baseline Epidemiologic Assessment of the Decade Prior to the Introduction of Pneumococcal and Meningococcal Vaccines. PLoS One, 8, 4-11.

http://dx.doi.org/10.1371/journal.pone.0064524

[14] Forgor, A.A. (2007) Meningococcal and Pneumococcal Meningitis.

[15] El-Tayib, W.E.H. (2004) University of Khartoum Faculty of Public and Environmental Health Department of Epidemiology.

[16] Trumah, R.B., Ayer, J. and Awunyo-Vitor, D. (2015) Climatic Variables and Disease Incidence in Ghana: A Study of Cerebrum Spinal Meningitis (CSM). Annual Research \& Review in Biology, 6, 304-315.

[17] Trotter, B. and Greenwood, C.L. (2007) Carriage Status in African Belt. p. 797.

[18] Forgor, A.A., Leimkugel, J., Hodgson, A., Bugri, A., Dangy, J.P., Gagneux, S., Smith, T. and Pluschk, G. (2005) Emergence of W135 Meningococcal Meningitis in Ghana. Tropical Medicine and International Health, 10, 1229-1234.

[19] Hodgson, A., Smith, T., Gagneux, S., Akumah, I. and Adjuik, M. (2001) Survival and Sequelae of Meningococcal Meningitis in Ghana. International Journal of Epidemiology, 30, 1440-1446.

[20] Zhang, Z.H. and Xu, X. (2013) Risk Factors Responsible for the Spread of Meningococcal Meningitis: A Review. International Journal of Educational Research, 1, 1-30. 
Submit or recommend next manuscript to OALib Journal and we will provide best service for you:

- Publication frequency: Monthly

- 9 subject areas of science, technology and medicine

- Fair and rigorous peer-review system

- Fast publication process

- Article promotion in various social networking sites (LinkedIn, Facebook, Twitter, etc.)

- Maximum dissemination of your research work

Submit Your Paper Online: Click Here to Submit

Or Contact service@oalib.com 